EPJ Web of Conferences 45, 01109 (2013)

DOI: $10.1051 /$ epjconf/20134501109

(C) Owned by the authors, published by EDP Sciences, 2013

\title{
Study regarding the influence of the crimping angle on the performances of the heat exchangers
}

\author{
O. Irimies,(Giurgiu) ${ }^{1}$, F. Bode ${ }^{1 \mathrm{a}}$ and D. Opruta ${ }^{1}$ \\ ${ }^{1}$ Technical University of Cluj Napoca, 400103, Faculty of Mechanics, Dept. of Mechanical Engeneering, Romania
}

\begin{abstract}
The aim of this study is to determine the geometry of a plate for heat exchanger with high heat flow and low values for pressure losses. For this, in Solid Work software, were designed three plate geometries with different crimping angles for the flow channels. Was analyzed the influence of the crimping angle $\beta$ on the fluid distribution and heat transfer. Also, were compared the data resulted from Computational Fluid Dynamics numeric simulation with the experimental ones for the plate heat exchangers with gaskets. The analysis of the vortices and temperature field distribution was achieved with the aid of simulation software Fluent. In order to validate the numerical simulation's results experimental research were carried out on a heat exchangers stand.
\end{abstract}

\section{Introduction}

This study aims to determine the geometry of a plate for heat exchanger with high heat flow and low values for pressure losses.

For this purpose, using Computational Fluid Dynamics (CFD), heat flow and pressure losses for plate heat exchangers were determined, for three plate geometers with different values of the crimping angle $\beta$. The aim of this study was to design three virtual models using $\beta=30^{\circ}, 45^{\circ}$ and $60^{\circ}$.

Plate geometry effects on the heat flow and pressure loss were studied varying mass flow for the working agent for each studied case.

The results of the simulation for the plate model with $\beta=60$ degree were compared with those obtained through experimental measurements.

It is known that corrugated plates of the plate heat exchangers increase the heat transfer area and creates turbulence in the flow, leading to increased heat transfer [1].

The characteristics of heat transfer and pressure loses are related to hydraulic diameter, heat transfer surface, number of channels and especially on the crimping angle $\beta$ (formed between the main direction of flow and the direction of inclination of a wavy channel) (figure 1). The last factor $(\beta)$, which characterizes the geometry of the plate, influences the flow regime by creating vortices and vortex areas, [2].

When choosing the turbulence model used in CFD numerical simulation was taken into account the fact that the flow plate heat exchangers must be modelled in detail, both in the central areas and near the wall (near the plate). The turbulence model that meets these parameters is $(\mathrm{k}-\omega)$ SST (Shear-Stress Transport) which uses specific functions "mixed ones" which activates turbulence model $(\mathrm{k}-\omega)$ in wall areas and model $(\mathrm{k}-\varepsilon)$ for flow in the central areas (between plates), thus allowing to use benefits of the 2 models $(\mathrm{k}-\varepsilon)$ and $(\mathrm{k}-\omega),[3,4,5,6]$.

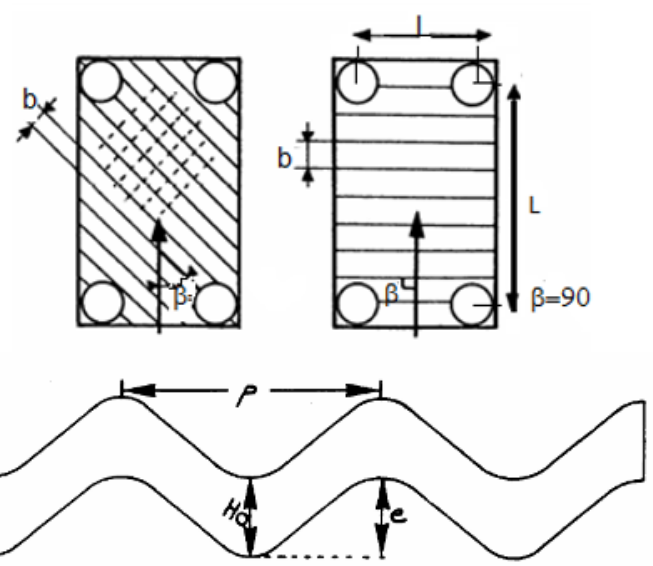

Fig $\square 1 \square$ Geometric elements of a plate

\section{CFD Numerical Simulations}

Numerical analysis for each plate model studied was conducted only on a segment of the active plates of a plate heat exchanger, due to the large computational resources needed for the CFD study.

${ }^{\mathrm{a}}$ Florin.Bode@termo.utcluj.ro 
For flow stabilization we have constructed a smooth part in the upstream part of the studied model, and to avoid backflow we made a smoothing part downstream of it (1 and 3 in figure 2).

Based on this observation the geometric models under study were design, as shown in Figure 2.

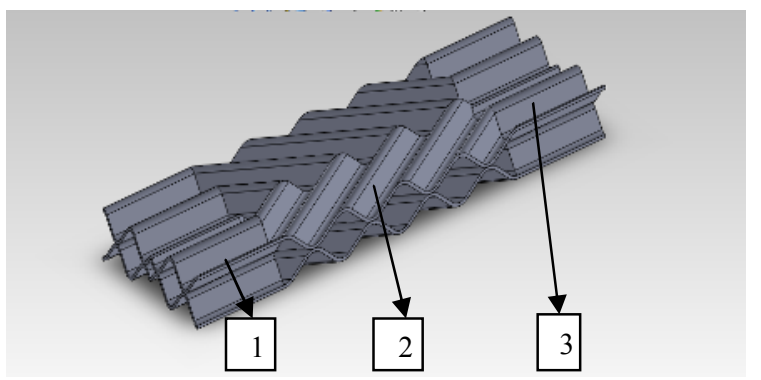

2a.

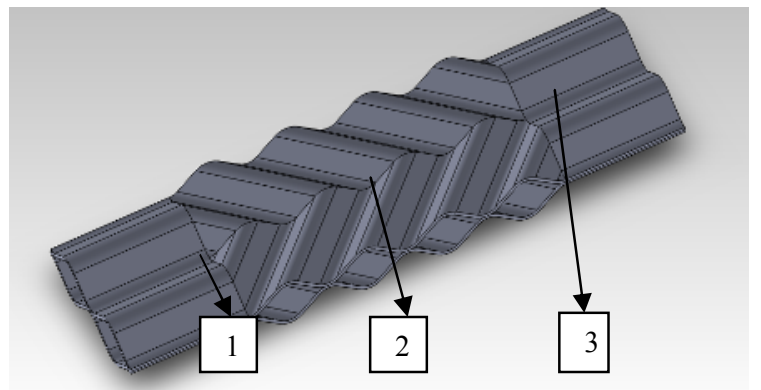

$2 b$.

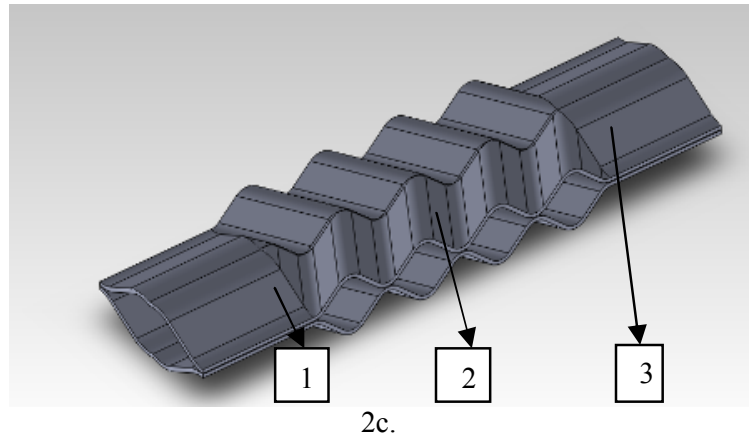

Fig $\square 2 \square$ Geometric models 2a. $\beta=30^{\circ}, 2$ b. $\beta=45^{\circ}$ 2c. $\beta=60^{\circ}$.

Models consist of two corrugated plates, stacked together in order to form the flow channel. Plate dimensions are: length of the plate $\mathrm{L}=40 \mathrm{~mm}$, width 1 $=20 \mathrm{~mm}$, waiving step $\mathrm{p}=10 \mathrm{~mm}$, height $\mathrm{H}_{0}=0.5$ $\mathrm{mm}$. The difference between the three models is represented by the crimping angle $(\beta)$, thus in Figure 2 are presented the 3 geometries $2 \mathrm{a}$. for $\beta=30^{\circ}, 2 \mathrm{~b}$. for $\beta$ $=45^{\circ}$ and in $2 \mathrm{c}$. for $\beta=60^{\circ}$. Geometrical models were realized in Solid Works 2011 and were imported into ANSYS - ICEM CFD, where the geometrical discretization (mesh) of the model was realized.

The mesh for the 3 models studied (Figure 3) was performed using tetrahedral elements, thinners in the entry areas and dense in the wavy areas. To achieve the grid were used approximately 13.8 million tetrahedral elements for each model under study.

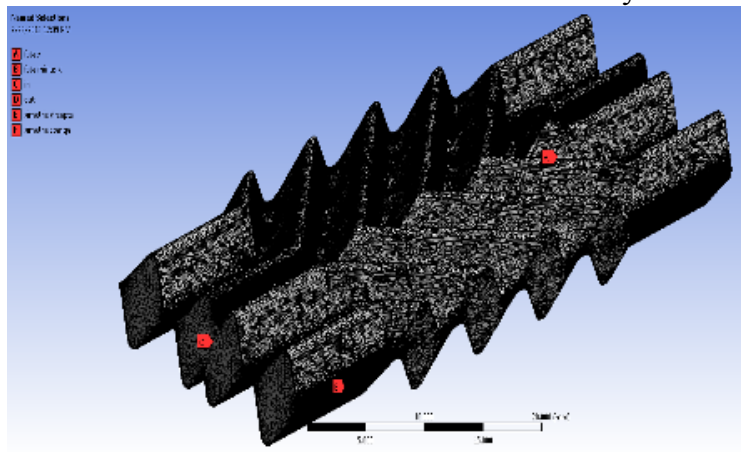

3a.

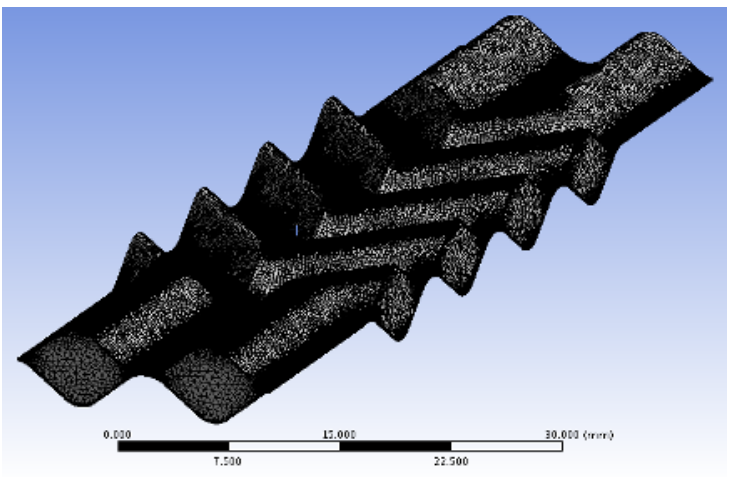

$3 b$.

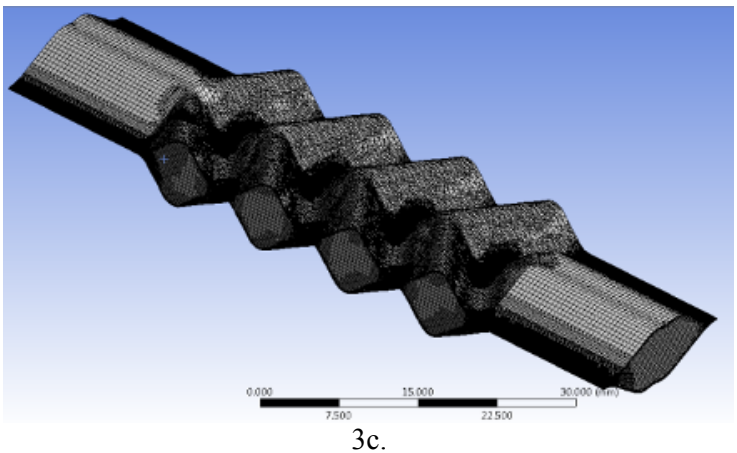

Fig $\square$ 3ロ Mesh

3a. $\beta=30^{\circ}, 3$ b. $\beta=45^{\circ} 3$ c. $\beta=60^{\circ}$.

As mentioned in the introductory chapter, numerical simulation was performed using turbulence model $(\mathrm{k}-\omega) \mathrm{SST}$.

Equations underlying the model of turbulence [7] are the continuity equation (relation 1), momentum conservation equation (relation 2), the transport equation (relation 3), kinetic energy transport equation (relation 4) and the transport equation for turbulent dissipation rate (relation 5):

$$
\frac{\partial u_{x}}{\partial x}+\frac{\partial u_{y}}{\partial y}+\frac{\partial u_{z}}{\partial z}=0
$$




$$
\begin{aligned}
& u_{x} \frac{\partial u_{i}}{\partial x}+u_{y} \frac{\partial u_{i}}{\partial y}+u_{z} \frac{\partial u_{i}}{\partial z}=\frac{1}{\rho} \\
& \frac{\partial p}{\partial x_{i}}+\frac{\partial p}{\partial y_{i}}+\frac{\partial p}{\partial z_{i}}+v \frac{\partial^{2} u_{i}}{\partial x^{2}}+\frac{\partial^{2} u_{i}}{\partial y^{2}}+\frac{\partial^{2} u_{i}}{\partial z^{2}} \\
& u_{x} \frac{\partial}{\partial x}+u_{y} \frac{\partial}{\partial y}+u_{z} \frac{\partial}{\partial z}=a \frac{\partial^{2} t}{\partial x^{2}}+\frac{\partial^{2} t}{\partial y^{2}}+\frac{\partial^{2} t}{\partial^{2}} \\
& \frac{\partial}{\partial}(\rho k)+\frac{\partial}{\partial x_{i}}\left(\rho k u_{i}\right)=\frac{\partial}{\partial x_{j}} \Gamma_{k} \frac{\partial x_{j}}{\partial x_{j}}+\tilde{G}_{k} Y_{k}+S_{k} \\
& \frac{\partial}{\partial}(\rho \omega)+\frac{\partial}{\partial x_{i}}\left(\rho \omega u_{i}\right)=\frac{\partial}{\partial x_{j}} \Gamma_{\omega} \frac{\partial \omega}{\partial x_{j}}+G_{\omega} Y_{\omega} \\
& +D_{\omega}+S_{\omega}
\end{aligned}
$$

where:

- $\quad \mathrm{u}$ - fluid velocity, in $\left[\mathrm{m} \mathrm{s}^{-1}\right]$;

- $\quad \rho$ - fluid density, in $\left[\mathrm{kg} \mathrm{m}^{-3}\right]$;

- $\quad \mathrm{p}$ - fluid pressure, in $\left[\mathrm{N} \mathrm{m}^{-2}\right]$;

- $\quad v$ - cinematic viscosity, in $\left[\mathrm{m}^{2} \mathrm{~s}^{-1}\right]$;

- $G_{k}$ - is the generation coefficient of turbulent kinetic energy due to gradients of medium velocity;

- $G_{\omega}$ - represent the specific rate of dissipation for turbulent kinetic energy;

- $\quad \Gamma_{\mathrm{k}}$ şi $\Gamma_{\omega}$ represents the effective diffusion of $\mathrm{k}$, respectively $\omega$;

- $\quad Y_{k}$ şi $Y_{\omega}$ are the effective difusion of $k$ and $\omega$;

- $\quad D_{\omega}$ - is a diffusion coefficient;

- cartesian coordinate system is used.

Imposed boundary conditions were the same for all models studied. It was imposed the primary agent temperature of $80{ }^{\circ} \mathrm{C}$ and for the secondary agent (the cold one) $20{ }^{\circ} \mathrm{C}$. Flow speed for the two agents was imposed at $0.5 \mathrm{~m} / \mathrm{s}$. To simplify the model was considered that the secondary agent (the cold one) crosses the space formed between the plates and that the plates were at the primary agent temperature.

In this study we used a "2nd order upwind" to solve the system of five equations. Regarding the accuracy of the results, it was imposed a criterion of convergence for all residual variables of $10^{-4}$, [8].

The results of this study (in all 3 cases) suggest that fluid flow is mainly oriented in the interior of the wavy areas and it follows them (Figure 4 a, b, c). Note that the central layer in the fluid follows the length of the wavy channel formed between the two plates. Layers of fluid near the wall plate follows the wavy channel in the direction of the crimping angle $\beta$, then intersect and mix with remaining fluid. It can be seen that in the wavy areas turbulences occurs and the flow is more pronounced in these areas. This type of fluid flow behavior is also described by Focke \& Knibbe [9], which made visual observations of the flow between two corrugated overlapping plates. This confirms that, when the liquid enters in a wavy area most of it follows it until it reaches the side wall, and is again directed to the wavy area. This type of behavior is similar to that resulting from CFD simulation performed.

It seems that in both cases, much of the liquid will follow the wavy areas, leading to the creation of turbulence, which is reflected in increased heat transfer.
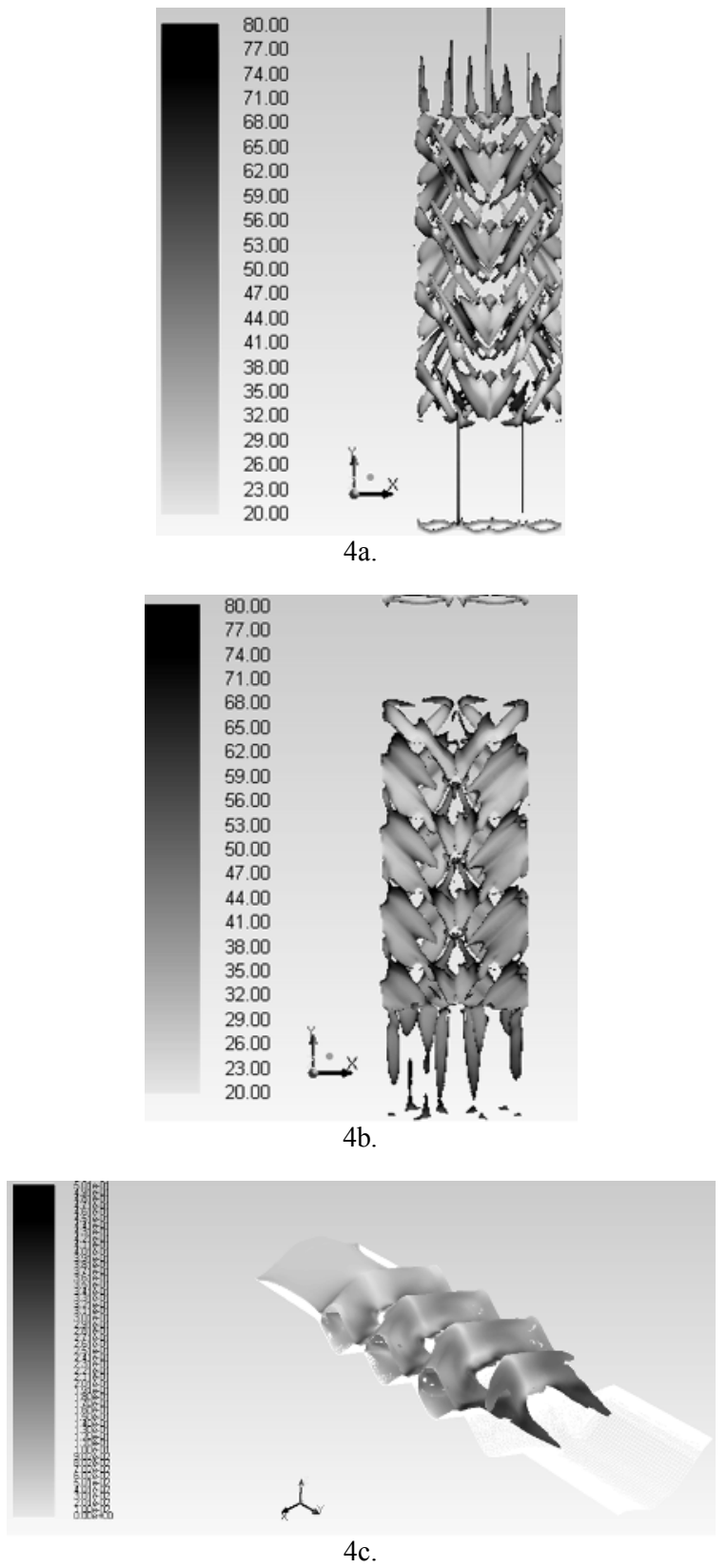

Fig $\square 4 \square$ Vortices izosurface colored by velocity 4a. $\beta=30^{\circ}, 4$ b. $\beta=45^{\circ} 4$ c. $\beta=60^{\circ}$. 
Figure 5 represents the temperature field in the liquid layer formed between two adjacent plates. This is shown in the middle section of the plate in the $x-y$ plane. For the first and the third model $\left(\beta=30^{\circ}\right.$ and $\beta$ $=60^{\circ}$ ) fluid enters in the field at the bottom, while the second model $\left(\beta=45^{\circ}\right)$ fluid enters through the top. The temperature fluid entry in this field is $20^{\circ} \mathrm{C}$. Fluid during passage through the plate, take heat from the plate. The best heat transfer was achieved for $\beta=30^{\circ}$ model, the working fluid warming with $25^{\circ} \mathrm{C}$.

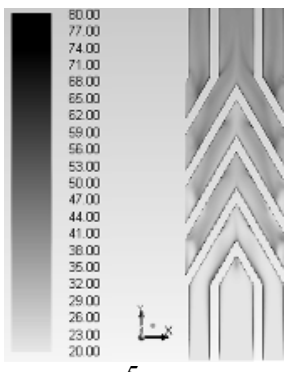

5 a.

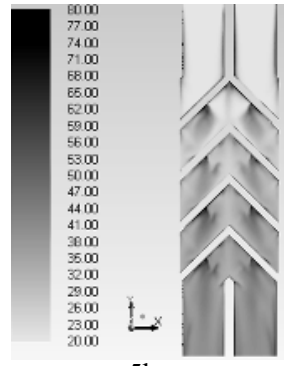

$5 b$.

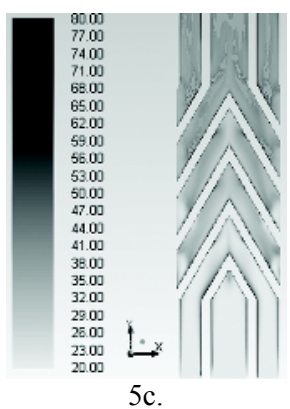

Fig $\square$ 5 $\square$ Temperature field 4a. $\beta=30^{\circ}, 4$ b. $\beta=45^{\circ} 4 \mathrm{c} . \beta=60^{\circ}$.

\section{Experimental investigations}

Experimental investigations were performed on experimental stand of heat exchangers, shown in Figure 6.

The installation consists of three main circuits: the primary circuit of hot water, the secondary circuit of cold water and the command circuit, presented in figure 7 .

The experimental facility is equipped with sensors for pressure, flow rate and temperature for both circuits, allowing readings in general switchboard of the stand.

The overall heat transfer coefficient $\mathrm{k}$ and heat flow were determined experimentally.

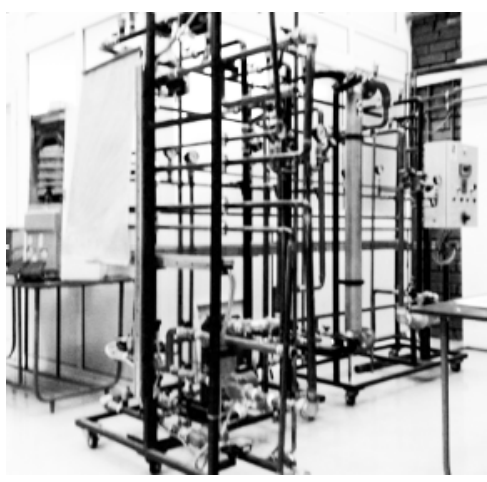

Fig $\square$ 6ロ Heat exchenger testing stand

An existing heat exchanger model was used for the experimental part. Its main characteristics are presented in Table 1:

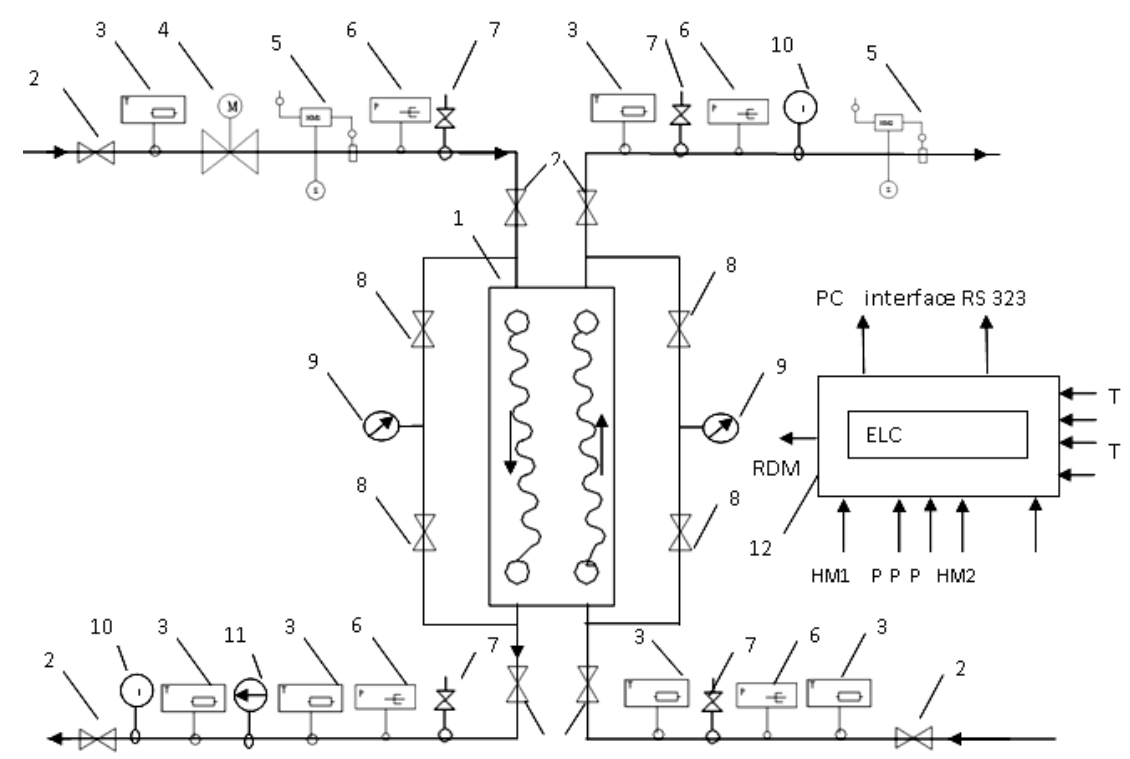

Fig $\square$ 7 The schematic diagram

1 - SCP plate heat exchanger, 2 - valve, 3 - differential temperature sensor, 4 - RDM motorized flow controller, 5 - energy meters for the primary HM1, HM2 for secondary agent, 6 - pressure sensor, 7 - air vent, 8 - sequential valves, 9 manometer, 10 - thermometer, 11 - PC recirculation pump, 12 - ELC Electric control system. 
Table 1 Heat exchanger characteristics

\begin{tabular}{|l|l|l|c|c|}
\hline & Parameter & U.M. & $\begin{array}{l}\text { Hot } \\
\text { agent }\end{array}$ & $\begin{array}{l}\text { Cold } \\
\text { agent }\end{array}$ \\
\hline 1 & $\begin{array}{l}\text { Inlet } \\
\text { temperature }\end{array}$ & $\mathrm{C}$ & 80 & 20 \\
\hline 2 & $\begin{array}{l}\text { Outlet } \\
\text { temperature }\end{array}$ & $\mathrm{C}$ & 50 & 50 \\
\hline 3 & $\begin{array}{l}\text { Pressure } \\
\text { losses }\end{array}$ & $\mathrm{k} \mathrm{Pa}$ & 2.56 & 2.55 \\
\hline 4 & Heat capacity & $\mathrm{k} \mathrm{W}$ & \multicolumn{2}{|c|}{25} \\
\hline 5 & $\begin{array}{l}\text { Number of } \\
\text { plates }\end{array}$ & & \multicolumn{2}{|c|}{10} \\
\hline 6 & $\begin{array}{l}\text { Effective heat } \\
\text { transfer } \\
\text { surface }\end{array}$ & $\mathrm{m}^{2}$ & \multicolumn{2}{|c|}{0,8} \\
\hline
\end{tabular}

\section{Results and discussions}

Figure 8 shows the effect of mass flow and crimping angle on the overall heat transfer coefficient k. According to the chart, for each model analyzed, there is a proportional increase of overall heat transfer coefficient with the increase of mass flow. The geometric model with the lowest crimping angle, subject the working fluid to more abrupt changes. That is causing modifications in velocity and in the direction of flow, thus increasing the contact time of the fluid with the plate, so leading to increasing heat transfer.

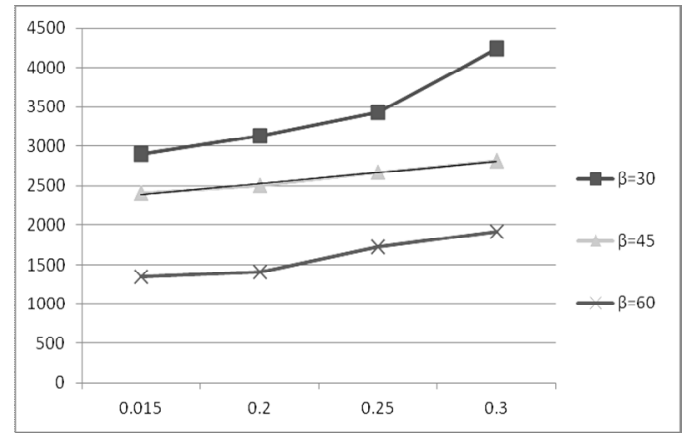

Mass Flow Rate $\left[\mathrm{kg} \mathrm{s}^{-1}\right]$

$\mathbf{F i g} \square 8 \square$ Heat transfer coefficient versus mass flow rate

Figure 9 shows the effect of mass flow and crimping angle on the heat flow. From the heat flow equation:

$$
Q=k \times S \times \Delta T(6),
$$

results that it depends on the overall heat transfer coefficient, of heat exchange surface and the difference of temperature between inlet and outlet of the area understudy. Therefore heat flow follows the same trend (of increase) with increasing of the mass flow. This graph also shows that geometry with the lowest crimping angle has the best results.

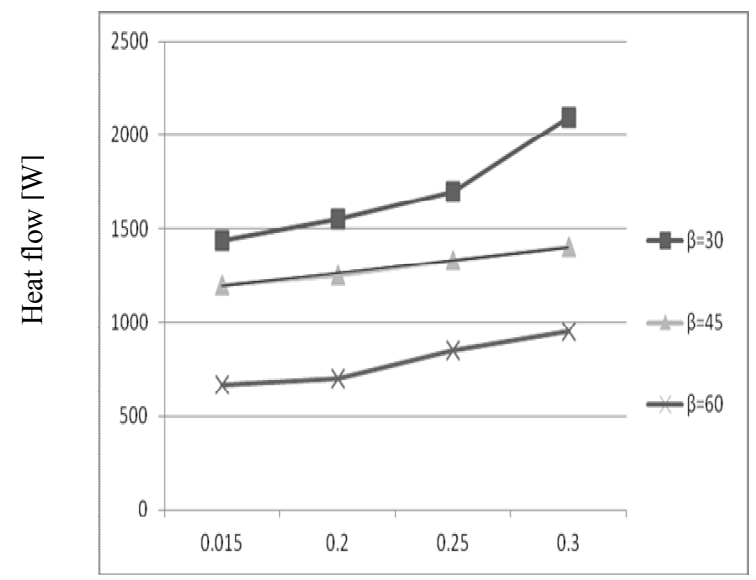

Mass Flow Rate $\left[\mathrm{kg} \mathrm{s}^{-1}\right]$

Fig $\square$ 9 Heat flow versus mass flow rate

The chart presented in Figure 10 shows the influence of mass flow and crimping angle over pressure loss. It may be observed that the lowest pressure drop were obtained for geometry with the crimping angle $\beta=60^{\circ}$. This is normal and is because the geometry is much smoother than the other two, which makes turbulence to not be so intensive.

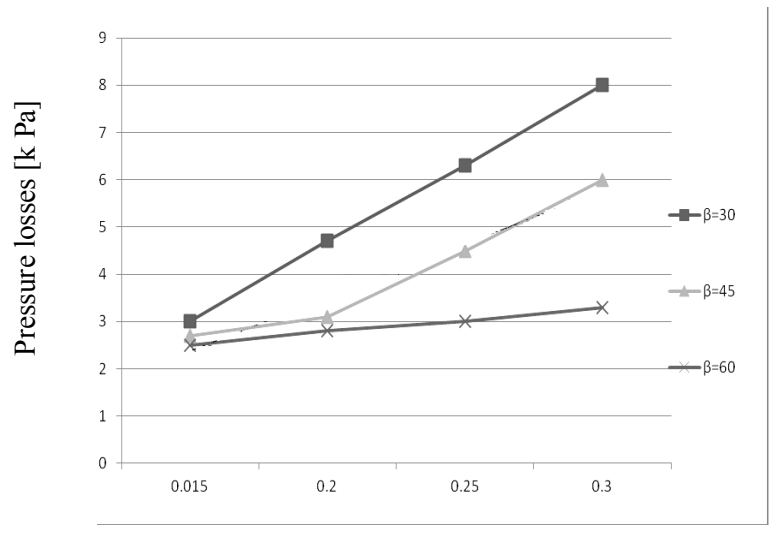

Mass Flow Rate $\left[\mathrm{kg} \mathrm{s}^{-1}\right]$

Fig $\square$ 10 $\square$ Pressure drops versus mass flow rate

In Figure 11 are compared the experimental results with numerical simulation for the third geometry that has a crimping angle $\beta=60^{\circ}$. The graph shows the variation of overall heat transfer coefficient depending on the mass flow of secondary agent. From the graph is observed increasing the overall heat transfer coefficient along with the increasing flow rate for both the CFD simulation results and the ones obtained experimentally.

The two curves are almost identical, which demonstrates that research, both numerical and experimental, have been carried out correctly. 


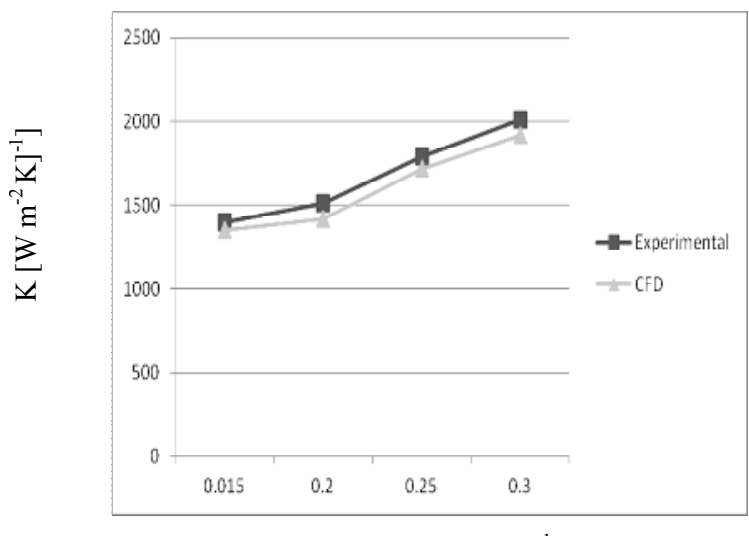

Mass Flow Rate $\left[\mathrm{kg} \mathrm{s}^{-1}\right]$

FiJ $\square \mathbf{1 1} \square$ Heat transfer coefficient versus mass flow rate

\section{Conclusions}

This paper presents a CFD numerical study over a plate of heat exchangers. For this study were designed 3 models of plates with different crimping angles: $\beta=$ $30^{\circ}, \beta=45^{\circ}$ and $\beta=60^{\circ}$.

Both the overall heat transfer coefficient and pressure losses have a tendency of growth with increasing mass flow rate, as shown in Figure 8 and 9.

In terms of heat transfer is recommended to use plate geometries with a crimping angle as small, because the heat transfer is more intense. This is due to changes that appear in agent flow velocity which leads to the formation of turbulence.

Lowest pressure drop were obtained for geometry with crimping angle of 60 degrees. This is one sinuous geometry shows no major changes of flow section, and thus the pressure losses are acceptable, as is shown in Figure 9.

Experimentally results for the geometry with 60 degree value of crimping angle are similar to those obtained from simulation.

\section{Acknowledgment:}

This paper was supported by the project "Improvement of the doctoral studies quality in engineering science for development of the knowledge based society-QDOC" contract no. POSDRU/107/1.5/S/78534, project co-funded by the European Social Fund through the Sectorial Operational Program Human Resources 2007-2013.

\section{References}

1 T.A. Rush, T.A. Newell, A.M. Jacobi, Int. J. Heat Mass Transfer 42, 1545-1553, (1999).

2 Jialing Zhu, Wei Zhang, Geothermics, 33, 337347, (2004)

3 Menter, F., Esch, T., Congress of Mechanical Engineering (COBEM), 16 (2001).
4 Kanaris, A.G., Mouza, A.A., and Paras, S.V., 83 460-468, (2005).

5 Pelletier, O., Strömer, F., Carlson, A., ASHRAE Transactions, 111(1) 846-854, (2005).

6 Ansys 12.0 Theory Guide

7 R. Resiga, Ed. Orizonturi Universitare, Timisoara, (1999)

8 Salim M. Salim, and S.C. Cheah, Engineers and Computer Scientists 2, (2009).

9 Focke, W.W., Knibbe, J.Fluid Mech., 165, 73-77, (1986) 